\title{
Rebuilding the health care system in Afghanistan: an overview of primary care and emergency services
}

\author{
John R. Acerra • Kara Iskyan • Zubair A. Qureshi • \\ Rahul K. Sharma
}

Received: 14 December 2008 / Accepted: 20 April 2009 / Published online: 5 June 2009

(C) Springer-Verlag London Ltd 2009

\begin{abstract}
Developing nations have many challenges to the growth of emergency medical systems. This development in Afghanistan is also complicated by many factors that plague post-conflict countries including an unstable political system, poor economy, poor baseline health indices, and ongoing violence. Progress has been made in Afghanistan with the implementation of the Basic Package of Health Service (BPHS) by the Ministry of Public Health in an effort to provide healthcare that would
\end{abstract}

The views expressed in this paper are those of the author(s) and not those of the editors, editorial board or publisher.

\section{J. R. Acerra $(\bowtie)$}

Department of Emergency Medicine, University of Pittsburgh,

230 McKee Place, Suite 500,

Pittsburgh, PA 15213, USA

e-mail: acerraj@upmc.edu

e-mail: jracerra@yahoo.com

\section{K. Iskyan}

Departments of Emergency Medicine and Internal Medicine,

Allegheny General Hospital,

320 E. North Avenue,

Pittsburgh, PA 15212, USA

e-mail:kmi5+@pitt.edu

\section{Z. A. Qureshi}

Department of Infectious Disease, University of Pittsburgh,

Pittsburgh, PA, USA

e-mail: zaq1@pitt.edu

\section{R. K. Sharma}

Department of Infectious Diseases and Microbiology,

Graduate School of Public Health, University of Pittsburgh,

A419 Crabtree Hall, 130 DeSoto St.,

Pittsburgh, PA 15261, USA

e-mail: rks23@pitt.edu have the most cost-effective impact on common health problems. Trauma and trauma-related disability were both identified as priorities under the BPHS, and efforts have begun to address these problems. Most of the emergency care delivered in Afghanistan is provided by the military sector and non-governmental organizations. Security, lack of infrastructure, economic hardship, difficult access to healthcare facilities, poor healthcare facility conditions, and lack of trained healthcare providers, especially women, are all problems that need to be addressed. The long-term goal of quality healthcare for all Afghan citizens will only be met by a combination of specific goaloriented projects, foreign aid, domestic responsibility, and time.

Keywords Emergency medical services · Afghanistan · Emergency medicine $\cdot$ Health care

\section{Introduction}

Afghanistan faces a significant challenge to creating a functional medical system in a post-conflict setting (although Afghanistan may be considered an "intra"-conflict setting). A low-income country recovering from decades of strife, the health care system has been in disarray for many years. Rebuilding the health care system in Afghanistan is currently being undertaken by a number of groups, including the Afghan government, several nongovernmental organizations (NGOs), and the US government. While some progress has been made, many hurdles remain. This article reviews the state of health care in Afghanistan, progress that has been made so far, and the challenges that 
lie ahead as efforts to improve the country's health care system continue.

\section{Background}

Afghanistan borders Pakistan, Iran, China, and the Central Asian Republics of Turkmenistan, Uzbekistan, and Tajikistan (Fig. 1) [1]. Following the conclusion of the 10-year invasion and war with the Soviet Union, which lasted from 1979 to 1989 , Western interest and support faded. Internal factions fighting for control destroyed much of Afghanistan's infrastructure, including what limited health care facilities existed. An ineffective government under the Taliban regime also contributed to an ineffective health care system [2]. Since the Taliban were deposed in 2001 by the US invasion, health care delivery has been mainly through NGOs.

Afghanistan has some of the worst health indices in the world (Table 1). Afghanistan ranked 173 out of 178 in the United Nations Human Development Index in 2004 [3]. Many infectious diseases such as acute respiratory infections, diarrheal diseases, measles, and malaria contribute to the burden of disease. Malnutrition, physical trauma, psychological trauma, and human rights abuses are also significant problems in the country $[4,5]$.

Since 2001, Afghanistan's health status has improved slowly, but much still needs to be done [6]. Emergency medicine in Afghanistan has not been developed or

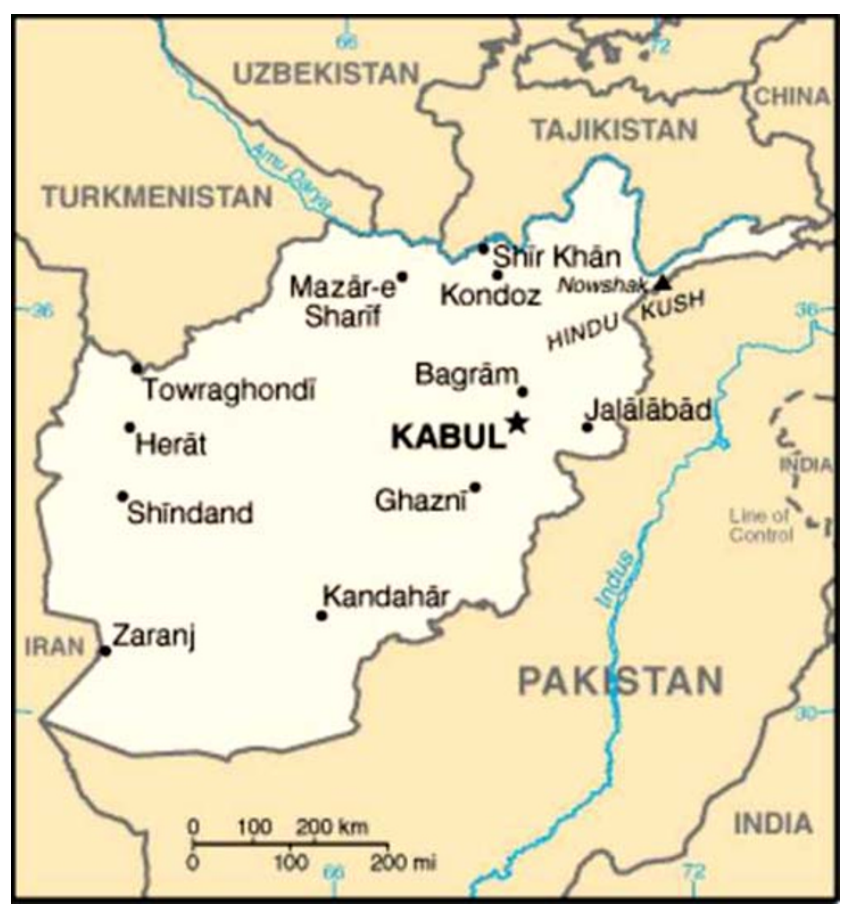

Fig. 1 Afghanistan and its neighbors
Table 1 Health indices in Afghanistan

\begin{tabular}{lll}
\hline & 2000 & 2006 \\
\hline Maternal mortality (per 100,000 live births) & & 1800 \\
Infant mortality (per 1,000 live births) & 165 & 165 \\
Under age 5 mortality (per 1,000 live births) & 257 & 257 \\
Life expectancy & 41 years & 42 years \\
Women with antenatal care & $4.6 \%$ & $32.2 \%$ \\
Skilled attendant delivery & $6 \%$ & $18.9 \%$ \\
\hline
\end{tabular}

recognized as a specialty. Outside US military and NATO hospitals, reliable emergency services are not available for the public [7]. Very poor roads and lack of vehicles make ambulance access difficult for civilians.

\section{Steps taken thus far to rebuild the health care system in Afghanistan}

The Afghan National Security Forces (ANSF), comprised of the Afghan National Army (ANA) and the Afghan National Police (ANP), provide some health care, much of which is tertiary care; however, continued international support for the ANSF is crucial for its maintenance. Most of the tertiary services provided by the ANSF are in Kabul, with regional hospitals in Kandahar, Gardez, Mazar-e Sharif, and Herat. Currently $82 \%$ of the entire population lives in districts where primary care services are provided by NGOs under contracts with the Ministry of Public Health of Afghanistan or through grants [8]. Much money and effort has been put into establishing tertiary care hospitals, but a coordinated health care infrastructure has not yet been developed in this country [9]. Consequently, many are still living without access to primary health care [10]. An estimated $70 \%$ of medical programs in the country have been implemented by aid organizations [11]. Although these organizations are somewhat successful, access to health care remains a problem [8]. There is a major shortage of a health care workforce in Afghanistan. World Health Organization data show that there are only 6,000 physicians and 14,000 nurses for a population of 28 million people [12].

\section{Basic Package of Health Services}

In March 2002, the Afghan Ministry of Public Health developed the Basic Package of Health Services (BPHS) as a guide for the health services that the Afghan government would commit to provide for all Afghan citizens (Table 2). Services were identified that would have the greatest impact on major health problems, be achievable given the 
Table 2 Basic Package of Health Services

limitations in infrastructure, be cost effective, and give equal access to health care in both rural and urban areas. Focus areas included maternal and newborn health, child health and immunizations, nutrition, communicable diseases, mental health, disability, and pharmaceutical supply [13]. The cost of delivering these BPHS was difficult to determine as health care was and still is provided by various groups, including the Afghan government, donors, and NGOs. Initial WHO estimates placed the cost at around US $\$ 40$ per person to start a rebuilding program in Afghanistan [14]. After careful consideration of the BPHS, several NGOs later estimated the cost of providing these services to $80 \%$ of the population at US $\$ 4.30-\$ 5.12$ per capita [15]. Six years ago only 9\% of Afghanistan's population of 28 million people had basic health coverage. Today nearly $85 \%$ of the population has access (within a 2-h walk) to basic health care. The goal for 2010 is $90 \%$ [16].

Health care delivery

Since the defeat of the Taliban in 2001, medical services in Afghanistan have been provided mostly by NGOs contracted through the Ministry of Public Health. Recently, the ANSF have been increasingly involved in providing health care in Afghanistan with the guidance of the US military. Emergency medicine is not yet a recognized or developed specialty in Afghanistan, but improving emergency care systems in the country will most likely improve health outcomes [13]. Full service emergency departments (EDs) exist for US military personnel at Bagram and other NATO military hospitals. While EDs do exist at some district hospitals and community health centers throughout the country, they are staffed by general practitioners with little or no emergency care training. Local emergency department administrators are not trained to manage EDs. This can be a problem for improving day-to-day operations of the departments.

Despite these challenges, some progress has been made in rebuilding the Afghan medical system according to the Center for Disaster and Humanitarian Assistance Medicine, particularly in emergency medicine. Much of this progress has been made in the military sector. Over 2,000 ANA combat medics have been trained in a standardized course adapted from US Army training focusing on combat casualty care. Over 700 ambulance vehicles have been purchased for ANSF use, but whether medics are properly trained to operate and use these vehicles and the appropriate distribution of them remains to be seen. Kabul Medical University has reduced its class sizes to manageable numbers, updated its nursing and medical school curricula, improved technology in teaching laboratories, and developed good relationships with the ANA and Ministry of Public Health. Graduate training programs in various fields exist, but specific training for emergency physicians is still lacking. Currently the plans for emergency services in Afghanistan are limited to the military sector. The focus on civilian health care is on primary care services, but as these improve, the long-term goal is to advance emergency care in the civilian sector as well.

\section{Challenges to the development of health care systems in Afghanistan}

There are many barriers to creating an accessible, effective, and sustainable health care system in Afghanistan. The main challenges of rebuilding Afghanistan's health care system include a lack of security, lack of infrastructure, economic hardship, poor coordination among government and health care providers, difficult access to health care facilities, unsuitable hospital conditions, and few trained health care workers, especially women.

\section{Security}

The security situation in Afghanistan remains unsafe and unpredictable. There are many threats such as suicide bombers, the widespread narcotics trade, and kidnapping for ransom. Afghanistan has more land mines and improvised explosive devices (IEDs) than any other country in the world [17]. In 2007, 45\% of Afghanistan's districts were not accessible to UN missions for extended periods of time due to security constraints and movement restrictions [18]. In addition to general insecurity, health centers and health care workers are targets. More than 50 health care centers have been closed due to violence. In 2004, more than 40 health and reconstruction workers were killed, including 5 who were murdered specifically for being health care workers. Due to this violence, at least 300,000 people lost access to primary care services last year [19]. Lack of security also affects those trying to seek medical care. Utilization of services in secure provinces is three times greater than in areas of active conflict [16]. Improved security is required for continued improvement in Afghanistan's emergency health care system. 
Lack of infrastructure

The lack of infrastructure in Afghanistan is manifested in many ways. A poor road network and near complete absence of railways makes some rural areas inaccessible during heavy winter snowfalls. Only $6 \%$ of Afghans have access to reliable electricity sources. Only $30 \%$ of households outside of cities have access to safe drinking water [3]. There are 2 landline telephones per 1,000 people, with half of these phones in Kabul [17]. Improvement of the health care system will require investment in transportation, electricity, safe water, and communications.

Health care quality and resources available vary widely from urban to rural areas. Hospitals outside of Kabul have a difficult time providing anything more than rudimentary care. For instance, when the International Council on Security and Development surveyed Mirwais Hospital, a regional hospital in Kandahar City, it was found to have 0.15 beds per 1,000 people compared to Kabul's 9.1 beds per 1,000 people. Mirwais Hospital does not have heat, thermometers, or record keeping. Electricity is intermittent and running water is usually dirty. It has one X-ray machine from the 1960s. Medications for hospitalized patients must be purchased from an outside pharmacy by family members and brought to the hospital. This situation is common throughout the country [20]. If there is medical equipment, most health care workers are not properly trained to operate or maintain it. Medical laboratories lack supplies and personnel. While primary care remains the appropriate focus of Afghanistan's health care system, hospitals need to be revitalized, especially for the practice of emergency medicine.

Economic instability

Another issue is economic instability. Nearly 70\% of Afghans live in extreme poverty with a $32 \%$ unemployment rate. Health care funding mainly comes from outside sources such as the European Commission, World Bank, and USAID [3]. While external funding is key, domestic support of health care must increase. External funding has unpredictable availability, frequent policy shifts, and the potential to end without warning [16]. Currently, domestic health care spending is a low priority with per capita spending on health care at $0.6 \%$ of the country's gross domestic product (GDP). Improvement in the economy, viable internal funding sources, and more spending by the Afghan government will improve access and affordability of health care.

\section{Communication and coordination}

The Ministry of Public Health contracts with NGOs for the majority of health care in Afghanistan. Although the
Ministry and NGOs have improved communication, lack of coordination on a provincial and district level results in inefficient and, at times, duplicated services. The ANA, ANP, and Ministry of Public Health have developed separate but redundant health care facilities to serve specific segments of the population. Lastly, a large number of Afghans use unregulated private sector health care. Integration and coordination among NGOs, the Ministry of Public Health, and various sectors of the Afghan government will be required to create a sustainable health care system for the entire country $[3,16]$.

Public health infrastructure

A discussion of health care access improvements is not complete without attention to basic needs. While basic health care is important, the lack of food, clean water, and shelter must also be addressed to improve community health. A survey of families regarding the health and nutrition of children under age 5 showed $59 \%$ of respondents experienced a shortage of basic material needs for at least 1 year [21]. Chronic malnutrition is rampant with $40 \%$ of Afghanistan's children underweight and 54\% with stunted growth [16]. Due to the recent years of drought and poor food security, nearly 5 million people depend on food assistance from the UN and other relief organizations [3]. Ensuring the population of Afghanistan has adequate food, water, and shelter must keep pace with improving health care access.

Health care workforce

Another obstacle for Afghanistan's health care system is the lack of qualified health care workers. During the Taliban years, many health care workers were killed or fled the country. The "brain drain" on Afghanistan left few health care workers. Of those who remain, medical training is inconsistent because of the lack of standardized training programs [17]. During the 1990s, medical schools were operated according to ethnic and religious rivalry. Consequently, medical students were often admitted through nepotism. A survey by the WHO showed $70 \%$ of nurses, midwives, and laboratory technicians did not meet minimum knowledge and skills standards when they were tested. The Ministry of Public Health cannot employ those trained by some NGOs because they do not meet the government's strict requirements. As a result, a nationwide survey indicated a shortage of least 7,000 physicians and 20,000 nurses, midwives, and allied health professionals [3, 22].

Despite the 11,000 medical students enrolled in 6 medical schools and 2,500-3,500 students enrolled in 9 Institutes of Health Sciences, problems with health education remain. The salary for physicians is too low for a 
reasonable standard of living, forcing physicians to practice at hospitals or public clinics in the morning and spend the afternoon in private clinics. The few residency training programs that exist provide minimal guidance in terms of lectures, clinical practice, or supervision [23]. Because there are two dominant languages in Afghanistan, courses must be offered in both Dari and Pashto. Upon completion of the programs, few health care workers desire to work in rural areas due to the poor living and working conditions, lack of education for their children, security issues, and poor transportation [3]. Although the immediate future for health care worker education is improving, there will be many struggles ahead as $60 \%$ of primary school aged children still do not receive an education. The illiteracy rate among women is $78 \%$ and among men $48 \%[13,24]$.

\section{Role of women}

While the number of overall health care workers is improving, the focus must be on women. Afghan societal norms dictate that only women can provide medical care for women. During the Taliban regime, women were forbidden from going to school; thus, virtually no female doctors or nurses were trained during this period. In 2002, only $21 \%$ of health care facilities had at least one female health care provider. Today nearly $60 \%$ of facilities have at least one woman to provide care. Access to health care for women is improving, but there are still many obstacles to overcome to decrease the health disparities between men and women $[18,22]$.

\section{The future of health care in Afghanistan}

The challenges of establishing a functional health care system in Afghanistan include those of a developing nation, post-conflict nation, and a combat zone. The long-term goal of quality health care for all citizens will only be met by a combination of specific goal-oriented projects, foreign aid, and domestic responsibility. Health care in Afghanistan is improving as evidenced by improved access to care, enhanced quality of patient care, and more knowledgeable health care workers in rural areas. These improvements show the effects of streamlined cooperation between the Afghan military, civilian government, and NGOs. Unfortunately, the country's health care system still needs significant improvement before it meets basic and higher-level health care needs. The focus on primary care is appropriate; primary care is the first line of defense and yields large dividends.

Currently, the future of the US military's humanitarian role in the continued rebuilding of medical systems in Afghanistan is uncertain as both the local military leader- ship in Afghanistan and the administration of the USA is in transition. While it is likely that the military will continue to be the driving force for this project, future plans are unclear at this time. President Obama is calling for a greater military presence in Afghanistan, making the future of humanitarian assistance in that country difficult to predict. The emergency training of the military should proliferate throughout the civilian health care systems. Civilian ambulance programs should be established in urban areas to begin emergency care. The WHO Essential Trauma Care Project can be used as a model to teach first responders with minimal training how to perform simple, inexpensive, and life-saving maneuvers such as airway management and hemorrhage control. Hospitals should be adequately stocked and staffed to ensure a patient with an emergency can be treated. Once emergency departments are properly staffed and stocked, more extensive prehospital training can be developed. A tertiary care system for the sickest patients should be established. With time, emergency medicine will develop to meet the specific needs of the people of Afghanistan. All of these future goals will require the continued involvement of foreign aid in Afghanistan as well as aggressive domestic economic development. The health care situation in Afghanistan today is dire, but improving. Time and commitment will ensure a brighter, healthier future for the nation of Afghanistan and its people.

Acknowledgment The authors would like to thank C. James Holliman, M.D. for his help providing background information on the state of emergency medicine in Afghanistan and final review of this paper.

Conflicts of interest None.

\section{References}

1. World Health Organization. Country profile, Afghanistan. Available via http://www.who.int/countries/afg/en/. Accessed 5 Nov 2008

2. Saguil A, McCormack MT (2008) Preparing for Afghanistan's medical future. CMAJ 178(8):990

3. World Health Organization. Country cooperation strategy for WHO and Afghanistan, 2006-2009. Available at http://www.who. int/countryfocus/cooperation_strategy/ccs_afg_en.pdf. Accessed 7 Nov 2008

4. World Health Organization. Mortality country fact sheet, Afghanistan. Available via http://www.who.int/whosis/mort/profiles/mort emro_afg_afghanistan.pdf. Accessed 5 Nov 2008

5. Bartlett LA, Mawji S, Whitehead S et al (2005) Where giving birth is a forecast of death: maternal mortality in four districts of Afghanistan, 1999-2002. Lancet 365:864-870

6. Loevinsohn B, Sayed GD (2008) Lessons from the health sector in Afghanistan: how progress can be made in challenging circumstances. JAMA 300(6):724-726

7. Kondro W (2007) Afghanistan: outside the comfort zone in a war zone. CMAJ 177(2):131-134

8. Waldman R, Strong L, Wali A (2006). Afghanistan's health system since 2001: condition improved, prognosis cautiously 
optimistic. Afghanistan Research and Evaluation Unit briefing paper series. Available via http://www.areu.org.af. Accessed 5 Nov 2008

9. Kondro W (2007) Where's the health in Afghanistan's reconstruction? CMAJ 177(3):233

10. Hansen PM, Peters DH, Viswanathan K et al (2008) Client perceptions of the quality of primary care services in Afghanistan. Int J Qual Health Care 20(6):384-391

11. Yusufzai A (2008) Poor medical facilities in Afghanistan mean patients turn to hospitals in Pakistan. BMJ 337:a2291. doi:10. 1136/bmj.a2291

12. World Health Organization. Core health indicators, Afghanistan. Available via http://www.who.int/whosis/database/core/core select process.cfm? country $=$ afg\&indicators $=$ healthpersonnel. Accessed $\overline{5}$ Nov 2008

13. Transitional Islamic State of Afghanistan (TISA), Ministry of Health. 2003. Basic Package of Health Services for Afghanistan. TISA, Kabul

14. Ahmad K (2001) UN agencies size up the task of rebuilding Afghanistan. Lancet 358:2060

15. Newbrander W, Yoder R, Debevoise AB (2007) Rebuilding health systems in post-conflict countries: estimating the costs of basic services. Int J Health Plann Manage 22:319-336

16. Health and Nutrition Sector Strategy (2007/08-2012/13). Afghan national development strategy. Feb 2008. Available via http://www. ands.gov.af/ands/final ands/src/final/sector strategies/Health\% 20\&\%20Nutrition $\% 20$ Sector $\% 20$ Strategy $\% 20-\% 20$ English.pdf. Accessed 7 Nov 2008

17. Sharp TW, Burkle FM Jr, Vaughn AF et al (2002) Challenges and opportunities for humanitarian relief in Afghanistan. Clin Infect Dis 34:S215-S228

18. UNICEF. Afghanistan humanitarian update 18 Jan 2008. Available via http://www.unicef.org/infobycountry/afghanistan_31224. html. Accessed 7 Nov 2008

19. ReliefWeb. Afghanistan: insurgency, insecurity threaten progress. July 2008. Available via http://www.reliefweb.int/rw/rwb.nsf/ db900SID/PANA-7GTGNY?OpenDocument11. Accessed 7 Nov 2008
20. War zone hospitals in Afghanistan: a symbol of wilful neglect. Senlis Afghanistan. The International Council on Security and Development. February 2007. Available via http://www.senliscouncil.net/ modules/publications/War_Zone_Hospitals. Accessed 7 Nov 2008

21. Mashal T, Takano T, Nakamura K et al (2008) Factors associated with health and nutritional status of children under 5 years of age in Afghanistan: family behaviour related to women and past experience of war-related hardships. BMC Public Health 8:301

22. Allison M. Nationwide survey and assessment of OB/gyn and skilled birth attendant training and graduates in Afghanistan. Hope worldwide Afghanistan, Center for Disaster and Humanitarian Assistance Medicine, July 2008

23. Richards T (2003) Afghanistan struggles to build post-conflict health care. BMJ 326(7394):837

24. USAID, Management Sciences for Health. Rural expansion of Afghanistan's community-based healthcare. Available at http:// www.msh.org/Afghanistan/index.html. Accessed 7 Nov 2008

John R. Acerra is an International Emergency Medicine fellow and Clinical Instructor of Emergency Medicine at the University of Pittsburgh and graduate student at the University of Pittsburgh Graduate School of Public Health.

Kara Iskyan is a resident physician in the Departments of Emergency Medicine and Internal Medicine at Allegheny General Hospital in Pittsburgh, PA and graduate student at the University of Pittsburgh Graduate School of Public Health.

Zubair A. Qureshi is a post-doctoral research scholar at the University of Pittsburgh in the Department of Infectious Disease and graduate student at the University of Pittsburgh Graduate School of Public Health.

Rahul K. Sharma is a paramedic with Northwest EMS and graduate student at the University of Pittsburgh Graduate School of Public Health. 